\title{
Physical and Mental Wellness among Students: Comparison of State-Level Model High Schools and Regular High Schools in China
}

\author{
Meixin Yu \\ The High School Affiliated to Renmin University of China, Beijing 10080, China \\ joannay_ymx@163.com
}

\begin{abstract}
The relationship between physiological and psychological well-beings among adolescents has always been studied extensively by researchers, yet few researches focuses on the impact of contextual factors such as school type, and demographic factors such as gender on the relationship between physical and subjective well-beings in the context of the Chinese educational system. This study measures Chinese high students' subjective well-being as measured by the Multidimensional Student Life Satisfaction Scale (MSLSS, Huebner, 2001) and physical well-being in terms of Body Mass Index (BMI). The impact of school type and gender are considered while investigating the relationship between the two measured variables. 331 high school students (58\% regular high school, $60.4 \%$ female) ranging in age between 14 and $21(\mathrm{M}=$ 17.47) responded to the questionnaire. Results suggest high school type has a significant impact on students' subjective well-being, and gender has a significant impact on BMI. Correlational analysis indicates that BMI is not correlated with subjective well-being. Findings are partially consistent with similar studies of adolescence's well-beings. Reasons for unique findings are discussed with the consideration of the unique character of the Chinese education system.
\end{abstract}

Keywords: subjective well-being, physical well-being, high school type, China.

\section{Introduction}

There are two categories of academic high schools in China: State Level Model (SLM) high schools and regular high schools. Namely, SLM high schools are better recognized than regular high schools in terms of factors such as environment, resources, and faculty (Pu, 1995). Noticeably, many parents in China push their children to go to SLM high schools, neglecting children's comprehensive wellness. Thus, the current study aims at investigating both the physical and subjective well-being among students in both SLM high schools and regular high schools, in order to better understand the impact of school type on students' general wellness.

\section{Literature Review}

\subsection{Physical Well-being among High School Students}

Physical well-being (PWB) is a set of attributes that people have or achieve relating to their ability to perform physical activity (U.S. Department of Health \& Human Services, 1996). To examine physical wellness, all sorts of measurements such as BMI and waist/hip ratio are used (Doll, Petersen, \& Stewart-Brown, 2000). The standard of unfitness, in this case overweight, obesity and underweight, in terms of BMI, is beyond the range of 18.5 to $25 \mathrm{~kg} / \mathrm{m} 2$ (Doll, Petersen, \& Stewart-Brown, 2000). Since this study is not in the medical category, it focuses on the general physical well-being measured by BMI, and it evaluates participants' fitness depending on standards of BMI.

\subsection{Subjective Well-being among High School Students}

According to Ryff and Keyes (1995), subjective well-being (SWB) consists of 6 dimensions: autonomy, environmental mastery, personal growth, positive relations with others, purpose in life and self-acceptance. Additionally, SWB is grounded in each person's experiences and includes overall evaluation of life (Diener, 1984). The author employs Huebner 's (1991) Multidimensional Students' Life Satisfaction Scale (MSLSS) as its function sticks coherently with the topic of this study. Studies 
have shown diverse factors that direct SWB. There is an association between self-esteem and perception of control, and life satisfaction (Casas et al, 2007). Chang (2003) and others found the predictive power of self-concept and family relations on life satisfaction. O'Donnell (2013) and others found that attribution style and autonomy both influence happiness. Lastly, support from school teachers and students positively correlate with general happiness (Chen \& Lu, 2009).

\subsection{Relationship between PWB and SWB}

On the one hand, physical factors such as physical education (P.E.) class and physical activities are correlated with high school students' SWB (Zhang \& Zhu, 2006). On the other hand, other studies have indicated that physical factors have no association with SWB. Stunkard and Sobal (1995) did not find any connection between BMI and psychological disturbances. Besides, changes in weight has been shown not related to changes in psychosocial functioning (Klesges, Klem, \& Klesges, 1992). Moreover, the correlation between physical activities satisfaction and negative self-esteem, external perception of control as well as perceived social support from friends was proved non-significant (Casas, Figuer, González, Malo, Alsinet, \& Subarroca, 2007).

This research not only will the research assess the relationship between SWB and PWB, the research will also compare and contrast the relationship in consideration of types of high school. Therefore, the independent variables are categorical: state-level model (SLM) high school or regular high school, which has been found in no former studies, and male or female.

\subsection{SLM and Regular High Schools in China}

To determine whether a high school is SLM, the school shall be rated in a system of three dimensions - management and benefit, physical evidence, and students honor - by representatives from Education Bureau. To be specific, management and benefit refers to the qualification of faculty, school climate, obedience of rules, and so on; physical evidence represents diversity, quality, and size of the physical components; students honor means all sorts of awards, both academic and literary, students win outside the school. If the final score passes the standard number, the school will be announced SLM high school. Generally, a SLM high school has faculty with higher level of education background, stronger physical conditions, and more capable students than a normal high school. Overall, there is study on students in SLM school only, but few previous researches focusing on wellness of students take the type of school that students go to into account.

\subsection{The Current Study}

To investigate the PWB and SWB among students in two types of high schools, 5 hypotheses are made:

First, students' high school type has a significant impact on their subjective well-being.

Second, students' high school type has a significant impact on their physical well-being.

Third, there is a significant correlation between subjective well-being and physical well-being.

Forth, gender has a significant impact on students' subjective well-being.

Fifth, gender has a significant impact on students' physical well-being.

\section{Methodology}

\subsection{Participants}

The research was done in Beijing and Guizhou in China. There is one SLM high schools in Beijing and one regular high school in Guizhou that participated. After the link of the questionnaire of was sent to each school, high school students (131 boys, 200 girls) selected randomly filled in the questionnaire online. Ultimately, 331 answers were collected (139 SLM, 192 regular), all of which are valid. Among the participants, the average age is 17 . Their heights range from 1.5 meter to 1.93 meter, and weights range from 37 kilograms to 115 kilograms. 


\subsection{Instrument}

Multidimensional Student's Life Satisfaction Scale (MSLSS) was first designed by Huebner (1991) to provide a profile of children's life satisfaction across key domains. The 40-item MSLSS, designed to be administrated to young people between the ages of 8 and 18, includes 7 items in family domain, 9 items in friends domain, 8 items in school domain, 9 items in living environment domain, and 7 items in self-domain, each item scored based on the participant's level of agreement. Since the research was done in China, the Chinese version of the scale was adopted.

\subsection{Reliability and Validity.}

The original scale is reliable, considering that the internal consistency has been found to be strong, ranging from 0.70 to low $0.90 \mathrm{~s}$ (Huebner, 2001), that test-retest coefficients have been found to be mostly in the range of 0.70-0.90 over intervals of 2-4 weeks (Huebner, 2001). The Chinese version of MSLSS has also been tested reliable (Ye et al, 2013): homogeneity reliability is 0.90 ; test results and re-test results have a positive correlation between 0.73 and 0.86 . The Chinese version has similar Cronbach's alpha coefficient as the original version in Huebner' s (1998) report. It is acknowledged that when the reliability coefficient is above 0.70 , the scale has solid reliability. (Guo, 2002) The reliability coefficient of the Chinese MSLSS is in the range of $0.70-0.85$, so the Chinese MSLSS has reliability.

The Chinese MSLSS has been proved to have criterion-related validity, content validity and construct validity (Guo, 2002), so Chinese MSLSS could be applied to Chinese students. Many previous studies used Chinese MSLSS (Meng et al, 2010; Lee \& Kimberlin, 2015). In conclusion, the Chinese version of MSLSS has both reliability and validity so it is a reasonable instrument for measuring adolescence life-satisfaction.

\subsection{Procedure}

In order to make the answers more scattered, the 6-point scale was changed into 7-point agreement scale. (1 represents "strongly disagree", 7 represents "strongly agree", some have reversed code accordingly) The research, made the online anonymous questionnaire with two sections: basic information (school type, gender, year of birth, height and weight), and the 7-point Chinese MSLSS. Participants completed the questionnaire online. Results collected, participants' ages were calculated based on their year of birth, and their BMI was calculated with the formula. Then, the sum of SWB scores were figured out. To test the first two hypothesis, $T$ test was employed to investigate the relationship between high school type and students' SWB and PWB. Pearson correlation test was applied to test hypotheses 3. Lastly, the researcher studied the influence of gender on SWB and PWB with $\mathrm{T}$ test, exploring hypothesis Four and Five.

\section{Results}

Independent sample T-tests were conducted to examine the first two hypotheses that high school type has significant impact on SWB and PWB. Demonstrated in Table 1, school type has a significant impact on students' subjective wellness, whereas it has no significant impact on BMI.

Table 1. Results of t-test and Descriptive Statistics for Subjective Well-being and Physical Wellbeing by High School Type

\begin{tabular}{|c|c|c|c|c|c|c|c|c|c|}
\hline \multirow[t]{3}{*}{ Outcome } & \multicolumn{6}{|c|}{ High School Type } & \multirow{3}{*}{$\begin{array}{l}\text { 95\% CI for Mean } \\
\text { Difference }\end{array}$} & \multirow{3}{*}{$t$} & \multirow{3}{*}{$d f$} \\
\hline & \multicolumn{3}{|c|}{ SLM School } & \multicolumn{3}{|c|}{ Regular School } & & & \\
\hline & $M$ & $S D$ & $n$ & $M$ & $S D$ & $n$ & & & \\
\hline SWB & 223.09 & 31.20 & 139 & 204.53 & 33.82 & 192 & $11.39,25.73$ & $5.16^{* *}$ & 310.38 \\
\hline BMI & 223.09 & 31.20 & 139 & 204.53 & 33.82 & 192 & $-9.95,74.20$ & -1.25 & 314.61 \\
\hline
\end{tabular}


The third hypothesis explores the correlation between SWB and SWB. Since the participants are from two types of high schools, the correlation test was done in separate context: among students in SLM high school, among students in regular high school, and among all high school students, regardless of the school type. All three correlational tests substantiate that there is no correlation between SWB and PWB. All the means, standard deviations, and correlations are displayed in Table 2 .

Table 2. Results of correlational test between SWB and PWB

\begin{tabular}{|c|c|c|c|c|c|c|c|}
\hline \multirow[t]{3}{*}{ Outcome } & \multicolumn{6}{|c|}{ Variables } & \multirow{3}{*}{ Pearson Correlation } \\
\hline & \multicolumn{3}{|c|}{ SWB } & \multicolumn{3}{|c|}{ BMI } & \\
\hline & $M$ & $S D$ & $n$ & $M$ & $S D$ & $n$ & \\
\hline SLM & 223.09 & 31.20 & 139 & 20.63 & 3.33 & 139 & -.07 \\
\hline Regular & 204.53 & 33.82 & 192 & 21.12 & 3.72 & 192 & .21 \\
\hline All & 212.32 & 33.96 & 331 & 20.91 & 3.57 & 331 & .069 \\
\hline
\end{tabular}

In addition to taking high school type into account, the research considers the role of gender in determining adolescents' SWB and BMI. In the contrary to the result of high school type, gender influences BMI significantly but has no such impact on SWB (see Table 3).

Table 3. Results of t-test and Descriptive Statistics for Subjective Well-being and Physical Wellbeing by Gender

\begin{tabular}{|c|c|c|c|c|c|c|c|c|c|}
\hline \multirow[t]{3}{*}{ Outcome } & \multicolumn{6}{|c|}{ Gender } & \multirow{3}{*}{$\begin{array}{l}\text { 95\% CI for Mean } \\
\text { Difference }\end{array}$} & \multirow{3}{*}{$t$} & \multirow{3}{*}{$d f$} \\
\hline & \multicolumn{3}{|c|}{ Male } & \multicolumn{3}{|c|}{ Female } & & & \\
\hline & $M$ & $S D$ & $n$ & $M$ & $S D$ & $n$ & & & \\
\hline SWB & 216.85 & 36.46 & 131 & 209.35 & 31.96 & 200 & $-.19,15.20$ & 1.92 & 207.99 \\
\hline PWB & 21.76 & 4.27 & 131 & 20.36 & 2.90 & 200 & $.56,2.25$ & $3.31 * *$ & 314.61 \\
\hline
\end{tabular}

$* \mathrm{p}<.05 ; * * \mathrm{p}<0.001$.

\section{Discussion}

\subsection{Evaluation of Results}

All five hypotheses either further enhance and extend existing theories, or reject partially. The first hypothesis was validated, featuring that days at school, involving interactions with teacher, peers, and environment, generally affect adolescents' satisfaction with life, underpinning Chen and Lu's (2009) statement that teachers and students' support correlate positively with general happiness. The reason that studying at a SLM high school generates different mental status than studying at a regular high school could be explained by Wu's (2017) research which attributes students' learning well-being to learning interest, academic record, learning motivation, etc.

The second hypothesis was falsified. To be specific, high school type has no significant impact on students' BMI. One study in the US (Alricsson, Landstad, Romild, \& Gundersen, 2008) that investigates the difference between students in vocational programs and counterparts in academic programs reaches an opposite conclusion: students in vocational programs reported poorer selfrelated health than those in academic programs, which implies the underlying relationship between type of school and physical health. The variance of conclusion might occur due to the particularity of Chinese education system. It is more accurate to conclude that the certain type of academic high school in China has no significant impact on students' PWB. One reason might be that BMI is also susceptible to subjective factors which are shaped by exposure to distinctive objective environment.

The third hypothesis was rejected by data. This may result from the feature of the MSLSS: this scale looks at the young's general life satisfaction with little consideration of physical factors like BMI, body shape, or exercise frequency, so the results do not associate with BMI. It can be true that even though physical factors such as P.E. class and physical activities are correlated with high school 
students' SWB (Zhang \& Zhu, 2006), BMI in particular has less to do with SWB, similar to Stunkard and Sobal's (1995) finding.

In addition, the study also explores gender's role in adolescents' PWB and SWB. The results could be supported by former studies (Lee \& Lee, 2000; Huebner, Laughlin, Ash, \& Gilman, 1998). Huebner, the original inventor of the MSLSS, and four other researchers (2004) utilized the scale on adolescents and found that mean total scores did not differ by sex, same as the result of this research. As experts (Lee \& Lee, 2000) have concluded, societal modernization fosters disordered eating in women, possibly via the gendered social constraints that accompany it. Women experience external stress about the aesthetic of body shape, resulting in the manifest difference made by gender to PWB.

\subsection{Conclusion}

As a conclusion, the study on PWB and SWB among students in both SLM high schools and regular high schools in China is a promising beginning in exploring Chinese educational system. The research reveals that type of high school has a significant role in SWB, whereas gender plays a significant role in PWB of adolescents. The results do not only expand new room for further study, but also inform the parents the significance of choosing the most fitting school for children, in order to help children, develop intellectual health, mental health, and physical health simultaneously.

\section{References}

[1]. Alricsson, M., Landstad, B. J., Romild, U., \& Gundersen, K. T. (2008). Physical activity, health, BMI and body complaints in high school students. Minerva pediatrica, 60(1), 19-25.

[2]. Breslow, L. (1972). A Quantitative Approach to the World Health Organization Definition of Health: Physical, Mental and Social Well-being. International Journal of Epidemiology.1(4), 347-355.doi:10.1093/ije/1.4.347.

[3]. Casas, F., Figuer, C., González, M., Malo, S., Alsinet, C., \& Subarroca, S. (2007). The WellBeing of 12 - to 16-Year-Old Adolescents and their Parents: Results from 1999 to 2003 Spanish Samples. Social Indicators Research, 83(1), 87-115. doi:10.1007/s11205-006-9059-1.

[4]. Chang, L., Mcbride-Chang, C., Stewart, S. M., \& Au, E. (2003). Life satisfaction, self-concept, and family relations in Chinese adolescents and children. International Journal of Behavioral Development, 27(2), 182-189. doi:10.1080/01650250244000182.

[5]. Chen, S. Y., \& Lu, L. (2009). ACADEMIC CORRELATES OF TAIWANESE SENIOR HIGH SCHOOLSTUDENTS'HAPPINESS. Adolescence, 44(176).

[6]. Devi, N., \& Kumari, R. (2010). Mental Health of Senior Secondary School Students in Relation to Certain Socio-Demographic Variables. International Transactions in Humanities \& Social Sciences, 2(2).

[7]. Diener, E. (1984). Subjective well-being. Psychological bulletin, 95(3), 542.

[8]. Doll, H. A., Petersen, S. E., \& Stewart-Brown, S. L. (2000). Obesity and physical and emotional well-being: associations between body mass index, chronic illness, and the physical and mental components of the SF-36 questionnaire. Obesity research, 8(2), 160-170.

[9]. Guo, Q., (2002). Principles and applications of psychological testing. People's Military Doctor Press. 38-39.

[10]. Heidrich, S. M., \& Ryff, C. D. (1993). Physical and mental health in later life: The selfsystem as mediator. Psychology and Aging, 8(3), 327.

[11]. Huebner, E.S., (2001). Manual for the Multidimensional Students' Life Satisfaction Scale. University of South Carolina, Department of Psychology. Columbia, SC. 
[12]. Huebner, E. S., Laughlin, J. E., Ash C., \& Gilman, R. (1998). Further validation of the Multidimensional Students' Life Satisfaction Scale. Journal of Psychological Assessment, 16, 118-134.

[13]. Huebner, E.S. (1991). Initial development of the Students' Life Satisfaction Scale. School Psychology International, 12, 231-243.

[14]. Huebner, E. S., Suldo, S., Valois, R. F., Drane, J. W., \& Zullig, K. (2004). Brief Multidimensional Students' Life Satisfaction Scale: Sex, Race, and Grade Effects for a High School Sample. Psychological Reports, 94(1), 351 - 356. doi:10.2466/pr0.94.1.351-356.

[15]. Klesges RC, Klem ML, Klesges LM. (1992). The relationship between changes in body weight and changes in psychosocial functioning. Appetite. 1992; 19:145-53.

[16]. Lee, J. J., \& Kimberlin, C. (2015). Life Satisfaction between Chinese-Immigrant Adolescents and Their Counterparts in the United States and China. Open Journal of Social Sciences, 3(04), 118.

[17]. Lee, S., \& Lee, A. M. (2000). Disordered eating in three communities of China: A comparative study of female high school students in Hong Kong, Shenzhen, and rural Hunan. International Journal of Eating Disorders, 27(3), 317-327.

[18]. Meng, X., Tao, F., Huang, Z., Hu, C., \& Wan, Y., (2010) The application of multidimensional student life satisfaction scale in Chinese teenagers. Chinese Mental Health Journal. 24(8), 613-618.

[19]. O'Donnell, S., Chang, K., \& Miller, K. (2013). Relations among autonomy, attribution style, and happiness in college students. College Student Journal, 47(1), 228-234.

[20]. Pu. T. (1995). Demonstrative evaluation and acceptance standards for ordinary senior middle schools. Journal of education. (9). 6-7.

[21]. Stunkard AJ, Sobal J. Psychosocial consequences of obesity. In: Brownell KD, Fairburn CG, eds. Eating Disorders and Obesity. New York: Guilford Press; 1995.

[22]. Wu, Z. (2017). The Influence Factors of High School Students' Learning Well-Being and Their Educational Suggestions. Advances in Psychology,7(6),819-823.

[23]. Ye, M., Li, L., Li, Y., Shen, R., Wen, S., \& Zhang, J. (2013). Life Satisfaction of Adolescents in Hunan, China: Reliability and Validity of Chinese Brief Multidimensional Students' Life Satisfaction Scale (BMSLSS). Social Indicators Research, 118(2), 515-522. doi: 10. 1007/ s11 205-013-0438-0.

[24]. Zhang, L., Zhu, J. (2006). A study on the relationship between happiness and physical education in high school students in Beijing and Chongqing. Journal of Beijing Sport University. 29(2). 192-194. 